\title{
COLLABORATIVE GOVERNANCE SEBAGAI INOVASI KEBIJAKAN STRATEGIS (STUDI REVITALISASI KAWASAN WISATA CAGAR BUDAYA BANTEN LAMA)
}

\author{
Ahmad Sururi \\ Fakultas Ilmu Sosial dan llmu Politik, Universitas Serang Raya, Indonesia \\ Email: ahmadbroer@gmail.com
}

\begin{abstract}
The complexity of the problems faced in the revitalization of Banten Lama cultural sanctuary is the problem of relocation of street vendors incorporated in the Kerosene Traditionist Association of Surosowan Banten Lama, the target of development (revitalization) of infrastructure that has not been achieved and the harmonious cooperation between stakeholders. The purpose of this research is to identify the priority and strategic issues and to develop the innovative model of Collaborative Governance based policy on the Revitalization study of Banten Lama Reserve Tourism Area. The research method used is qualitative descriptive approach with data collection technique through interview and observation and searching various sources and literature both from government documents and news media print and electronic, journal and books related to collaborative governance, policy innovation and revitalization Banten Long. The result of this research is the identification of priority and strategic issues of Revitaliasi Policy of Banten Lama Reserve Tourism Area namely bureaucratic structural dimension, socialization of revitalization and relocation of street vendors incorporated in Paguyuban Keragang Surososwan Banten Lama Traders. Furthermore, the development of innovative governance policy innovation model and revitalization stages include four components, namely the initial conditions consisting of identification of existing conditions, resources, basic considerations and economic political will; the second component is a commitment that includes processes and outcomes, beliefs, common understanding and internal / external legitimacy; the third component is institutional design consisting of structure and procedure, leadership and form of cooperation process; and the fourth component is the final condition that includes follow-up and sustainability.
\end{abstract}

Keywords: Collaborative Governance; Revitalization and policy innovationy;Banten Lama

\section{Pendahuluan}

Banten lama adalah sebuah wilayah di Provinsi Banten yang selama ini dikenal sebagai destinasi wisata religi dan dijadikan cagar budaya. Sebagai kawasan bekas peninggalan sejarah kerajaan Banten, daya tarik wisatawan dari berbagai daerah di Indonesia untuk mengunjungi berbagai situs bersejarah di Banten Lama sangatlah besar, destinasi wisatanya seperti; ziarah ke makam Sultan Hasanudin Banten, keraton surosowan, masjid agung Banten Lama, tempat pemandian bersejarah Watu Gilang dan Danau Tasik Kardi. Berdasarkan aspek kebijakan, pengelolaan dan penataan daerah wisata Banten lama merupakan kewenangan Pemerintah Kota Serang dan kenadziran Banten Lama. Tercatat sejak tahun 2010 
sejak kota Serang terbentuk, kewenangan kawasan wisata Cagar Budaya Banten Lama diserahkan kepada Pemerintah Kota Serang. Sedangkan dari aspek geografis dan administratif terdapat hubungan lintas wilayah antara Provinsi Banten dengan 2 wilayah di bawahnya yaitu Kabupaten Serang dan Kota Serang. Dengan demikian terdapat sebuah konsekuensi kerja sama dan strategi inovasi kebijakan antar pemerintahan daerah ditingkat provinsi dan Kabupaten/Kota dalam revitalisasi kawasan wisata cagar budaya Banten Lama. Hal tersebut dilakukan melalui mekanisme Collaborative Governance sebagai A governing arrangement where one or more public agencies directly engage non-state stakeholders in a collective decision-making process that is formal, consensus-oriented, and deliberative and that aims to make or implement public policy or manage public programs or assets. (Ansell \& Gash, 2007), oleh sebab itu proses pengambilan keputusan, komitmen bersama dan deliberatif menjadi point penting bagi seluruh stakeholder yang terlibat dalam inovasi kebijakan strategis collaborative governance. Selain itu
Inovasi kebijakan publik menjadi keharusan ketika kebijakan manual yang hanya berfungsi sekedar menggugurkan kewajiban pemerintah melahirkan berbagai kekecewaan dan kecemasan ditengah-tengah publik, khususnya yang menyangkut kepentingan hajat hidup orang banyak. (Dede Mariana, 2010 dalam Sururi, 2017).

Saat ini revitalisasi kawasan wisata cagar budaya Banten Lama melibatkan kerjasama antara berbagai pihak yaitu, pemerintahan provinsi Banten, Pemerintahan Kota Serang, Pemerintahan Kabupaten Serang dan Badan Pelestarian Cagar Budaya (BPCB) Banten yang tertuang dalam Memorandum of Understanding (MOU). Hal ini memerlukan pelibatan secara intensif dari berbagai stakeholder walaupun tentu saja mengandung implikasi yang cenderung kompleks dan tidak mudah pada tataran praktis. Typically, systems of collaborative governance have structures that display very complex features in a number of respects, this has implications for their practicality as governance mechanisms. (Huxham, Vangen, Huxham, \& Eden, 2000). Oleh sebab itu kerjasama ini 
memerlukan penanganan prioritas dalam pelaksanaannya pun sebagai bagian dari upaya dan tantangan bagi pemerintah daerah dalam mendorong proses sinergisitas sektor publik dengan partisipasi masyarakat terutama dengan masyarakat di sekitar kawasan Banten Lama dan Para Pedagang Kaki Lima yang tergabung dalam kelompok Paguyuban Pedagang Keraton Surososwan.

Berbagai penelitian tentang collaborative governance sudah banyak dilakukan, di antaranya dilakukan oleh Jung, Mazmanian dan Tang (2009) yang dilakukan di dua negara mengenai kerjasama antara Amerika Serikat dan Korea Selatan dalam negoisasi perumusan kebijakan dan pemberian layanan serta menunjukkan bagaimana sejumlah faktor terkait erat dengan dinamika dan kinerja pengaturan pengaturan collaborative governance $\mathrm{di}$ kedua negara yaitu pelibatan aktor dari berbagai organisasi, konflik distribusi dan pentingnya perencanaan kebijakan. Kemudian penelitian Tresiana dan Duadji (2017) tentang Kolaboratif Pengelolaan Pariwisata Teluk Kiluan yang menganalisis bagaimana prasyarat yang dimiliki dan diperlukan untuk penciptaan proses kolaboratif dalam pengelolaan pariwisata Teluk Kiluan sehingga proses kolaboratif tidak menghasilkan demokrasi semu tetapi bermanfaat bagi masyarakat, hasil penelitian menunjukkan bahwa terdapat persyaratan yang belum optimal dalam pengelolaan pariwisata Teluk Kiluan dan membutuhkan perubahan dalam strategi kebijakan melalui dukungan pemerintah, partisipasi masyarakat, manfaat langsung, penggunaan sumber daya lokal, penguatan kelembagaan lokal dan sinergi antar tingkat dan daerah dan menyimpulkan bahwa untuk dapat memenuhi prasyarat masyarakat kolaboratif dalam perencanaan pengelolaan pariwisata, maka perlu dikembangkan model pengelolaan pariwisata berbasis komunitas masyarakat. Selanjutnya penelitian Newman, Barnes, Sullivan dan Knops (2004) tentang pentingnya partisipasi publik dalam proses Collaborative Governance, hasilnya adalah terdapat kendala dalam proses inisiatif kebijakan pemerintah dan struktur politik. Selanjutnya penelitian tentang faktor budaya yang memengarhui pelaksanaan Collaborative Governance di Desa Budaya Brosot, yaitu: Hubungan 
Kekerabatan, Arisan, Jam Karet, Musyawarah Mufakat, Nggih ra Kepanggih, Ngaruhke, Gotong Royong dan Swadaya, Mokogi, Ngombyongi, dan Mosobodoa, Paternalistik dan orangnya sekitar itu itu saja dilakukan oleh Sambodo dan Pribadi (2016). Dan beberapa penelitian Collaborative Governance lain lain yang dilakukan Kurniasih, Setyoko dan Imron (2017), dan Mutiarawati dan Sudarmo (2017)

Dari berbagai penelitian tersebut, diketahui bahwa dalam proses Collaborative Governance diperlukan reformasi dengan mensinergikan berbagai perspektif pemangku kepentingan, lebih dekat dengan masyarakat, dan memperluas kerjasama dengan pihak lain untuk memenuhi kebutuhan sumber daya, dan perekrutan SDM. Sedangkan penelitian ini akan melakukan identifikasi isu-isu strategis dan menjadi prioritas dalam kebijakan collaborative governance serta menganalisis bagaimana pengembangan model inovatif kebijakan collaborative governance dalam revitalisasi kawasan wisata cagar budaya Banten Lama.

Kompleksitas permasalahan kawasan wisata cagar budaya Banten
Lama merupakan salah satu alasan mengapa kebijakan revitalisasi dilakukan melalui mekanisme collaborative governance. Misalnya persoalan relokasi Pedagang Kaki Lima (PKL) dari tempat yang lama ke tempat yang baru, Dalam hal ini peran pemerintah sebagai fasilitator dalam melakukan sosialisasi dan pendekatan secara persuasif kepada para pedagang kaki lima perlu terus dilakukan agar tidak menimbulkan resistensi dari para pedagang tersebut.

Salah satu bagian penting collaborative governance adalah ketersediaan barang dan jasa yang akan dipergunakan untuk kebutuhan pembangunan kawasan Banten Lama, akan tetapi lambatnya mekanisme lelang pengadaan barang dan jasa yang dilakukan oleh organisasi sektor publik mengakibatkan proses pembangunan menjadi terhambat dan tidak sesuai dengan waktu yang direncanakan, Diperlukan kemitraan yang bersifat kolektif pada tujuan bersama dalam setiap proses kolaborasi antara organisasi sektor publik, dan kemitraan tersebut akan berjalan secara efektif apabila terdapat sebuah model collaborative governance yang mampu mendorong 
sinergitas berbagai pihak yang terlibat secara aktif.

Moodel collaborative governance berdasarkan empat variabel dikemukakan oleh Ansel dan Gash (2007) yaitu sebagai berikut: conditions, institutional design, leadership, and collaborative process. Kemudian terdapat tiga komponen penting dalam mendorong desain kelembagaan dan kepemimpinan yaitu; time, task and target. (Doberstein, 2016)

Prasyarat mutlak inovasi kebijakan publik adalah terwujudnya gagasan dan ide dari pejabat publik sebagai entrypoint diimplementasikannya berbagai program-program dan kebijakan. Stakeholder Kota Serang sebagai leading sector revitalisasi kawasan wisata cagar budaya Banten Lama dituntut untuk mengembangkan sebuah model collaborative governance yang inovatif, kreatif dan adaptif terhadap persoalan dan kebutuhan masyarakat yang semakin dinamis.

Penelitian ini bertujuan untuk melakukan identifikasi isu-isu strategis dan prioritas serta melakukan pengembangan model inovatif kebijakan collaborative governance sehingga diharapkan akan memiliki dampak dan manfaat terhadap kebijakan akselerisasi dan sebagai rekomendasi kebijakan Collaboarative Governance dalam revitalisasi kawasan wisata Cagar Budaya Banten lama.

\section{Metode Penelitian}

Studi dilakukan di Kawasan Wisata Cagar Budaya Banten Lama. Metode yang digunakan adalah pendekatan deskriptif kualitatif yang menggambarkan isu-isu prioritas dan strategis Collaborative Governance Revitalisasi Kawasan Wisata Cagar Budaya Banten Lama, sedangkan teknik pengumpulan data dilakukan inventarisasi data primer dan sekunder. Untuk data primer diperoleh berdasarkan data empiris lapangan melalui tehnik: Wawancara mendalam (depth interview) dan Observasi non Partisipan dan Diskusi kelompok terarah (Focus Group Discussion). Sedangkan data sekunder meliputi penelusuran berbagai sumber dan literatur baik dari dokumen pemerintah maupun pemberitaan media massa cetak dan elektronik, jurnal dan buku-buku yang terkait dengan collaborative governance dan inovasi kebijakan. Selanjutnya data yang terkumpul, dianalisis dengan analisis 
kualitatif, dengan model interaktif Miles dan Huberman (1992).

\section{Hasil Dan Pembahasan}

\subsection{Identifikasi Isu-isu prioritas dan} strategis collaborative governance dalam Revitalisasi Kawasan Wisata Cagar Budaya Banten Lama

a. Dimensi Struktural Birokrasi antar Pemerintahan Daerah

Isu prioritas dan strategis yang pertama dan menjadi aspek penting yang harus menjadi komitmen bersama dalam collaborative governance adalah dimensi struktural birokrasi antar pemerintahan daerah, structural issues are important because they affect the way collalborative agendas are formed and implemented (Huxham et al., 2000), dalam hal ini, konsep collaborative governance dalam revitalisasi kawasan Wisata Cagar Budaya Banten Lama mensyaratkan setiap pemerintahan daerah mempunyai kesamaaan pemahaman tentang bagaimana formulasi dan implementasi kebijakan revitalisasi. Prinsip-prinsip kerjasama revitalisasi kawasan wisata cagar budaya Banten Lama dengan beragamnya keterlibatan stakeholder dan lintas organisasi sektor publik menjadi tantangan sekaligus potensi dalam mengatasi permasalahan. Collaborative Governance yang tertuang dalam Memorandum Of Understanding (MOU) sebagai pedoman pelaksanaan revitalisasi menjadi dokumen strategis yang harus ditaati oleh semua pihak.

Mengoptimalkan relasi struktural birokrasi organisasi sektor publik di Pemerintahan Daerah dapat menjadi opsi dalam mengatasi persoalan lambatnya proses lelang pengadaan barang dan jasa untuk kebutuhan pembangunan revitalisasi kawasan Banten Lama. Dalam hal ini organisasi sektor publik harus bersifat enabling linkage yaitu keterkaitan lembaga atau organisasi dengan penyediaan wewenang untuk bekerja mencapai sumber-sumber daya yang esensi dan diffusion linkage yaitu hubungan lembaga atau organisasi dengan orang atau kelompok-kelompok yang tidak terkumpul dalam suatu organisasi (Esman, 1972:33 dalam Torang, 2016:104-105)

Seperti yang tertuang dalam kutipan wawancara berikut ini yang menjelaskan tentang faktor penghambat mekanisme lelang guna mendukung 
revitalisasi kawasan wisata cagar budaya

Banten Lama yaitu sebagai berikut :

"Proses lelang untuk Banten Lama belum selesai. Namun, sudah ada beberapa lelang yang sudah ditayangkan. keterlambatan lelang bukan karena kesalahan pada pihaknya. Hal ini karena proyek pengadaan belum ada yang dilelang dan dokumen lelang masih dalam proses pengkajian oleh OPD terkait, dokumen masuk ke kita, kita kembalikan lagi ke OPD untuk dikaji ulang. Karena belum balik hasil kajiannya, enggak bisa lelang”. (Informasi wawancara dengan Kepala Biro Administrasi Pembangunan Provinsi Banten, Bapak Mahdani)

Dari hasil wawancara dapat dijelaskan bahwa terdapat kendala dalam proses lelang untuk revitalisasi pembangunan kawasan Banten Lama, yang disebabkan karena belum selesainya proses pengkajian oleh Organisasi Perangkat Daerah (OPD) yang berwenang. Berdasarkan hal tersebut dapat dianalisis bahwa terdapat indikasi belum terciptanya relasi antara birokrasi tentang penetapan target dan tujuan lelang yang diatur dalam kesepakatan bersama sehingga mengakibatkan terhambatnya pembangunan revitalisasi kawasan cagar budaya Banten Lama. b. Sosialisasi Revitalisasi Kawasan Cagar Budaya Banten Lama

Isu kedua yang menjadi isu prioritas dan strategis dan menjadi gagasan-gagasan konseptual terkait adalah sosialisasi revitalisasi kepada seluruh masyarakat. collaborative governance is therefore not advanced merely to satisfy a vague notion of more inclusive decision-making, but rather 'to engage different "ways of knowing" in the continuous processes of problem solving' (Feldman et al. 2006, 93 dalam Doberstein, 2016), dan upaya pendekatan partisipatif publik yang sudah dilakukan tidak hanya dilakukan pada kondisi awal atau pada saat launching gagasan revitalisasi akan tetapi harus dilakukan secara konsisten, hal ini bertujuan agar masyarakat mempunyai trust terhadap kebijakan revitalisasi.

Berdasarkan hasil wawancara, ditemukan fakta bahwa masyarakat masih mempertanyakan bagaimana kelanjutan revitalisasi setelah launching gerakan Banten Bebersih yang sudah dicanangkan Pemerintah Provinsi Banten pada tanggal 21 Juli 2017 sekaligus penandatanganan MOU. (Harian Umum Kabar Banten, 22 Juli 2017). Oleh sebab itu sosialisasi tidak hanya bersifat parsial akan tetapi 
harus dilakukan secara terus menerus dengan tujuan masyarakat mengetahui perkembangan program yang secara langsung akan melibatkan masyarakat. Dalam wawancara tersebut, dikemukakan, "kami mewakili masyarakat di daerah Banten Lama masih menunggu proses kelanjutan revitalisasi, launcing kan sudah tanggal 21 Juli 2017 kemaren, sekarang masih belum ada sosialisasi dan rencana lagi. (Wawancara dengan Sulaeman, penduduk lokal Banten Lama)

\section{c. Relokasi Pedagang Kaki Lima dari Kawasan Cagar Budaya Ke Kawasan Penunjang Wisata (KPW)}

Isu penting ketiga yang menjadi permasalahan dalam revitalisasi kawasan adalah relokasi pedagang kaki lima. Untuk kondisi saat ini, para Pedagang belum bisa direlokasi ke Kawasan Penunjang Wisata (KPW) atau tempat relokasi yang baru dikarenakan belum memadainya sarana penunjang seperti listrik, tempat sampah dan jalan lingkungan. Selain itu berdasarkan hasil wawancara dengan beberapa pedagang kaki lima yang tergabung dalam paguyuban pedagang Keraton Surosowan Banten Lama, para pedagang belum sepenuhnya menyetujui untuk di relokasi, penyebabnya adalah karena para pedagang kaki lima tersebut khawatir lokasi yang baru kurang strategis dan tidak dilalui oleh wisatawan yang berkunjung.

Mendorong Pemerintah Daerah untuk melakukan penataan Kawasan Penunjang Wisata (KPW) menjadi prioritas isu yang harus dilakukan, termasuk dalam hal ini dialog secara intensif dengan para pedagang kaki lima agar bersedia direlokasi ke tempat yang baru. Upaya dialog dan memposisikan pedagang kaki lima sebagai partner menjadi prinsip utama dan sebagai bagian dari tata kelola Collaborative Governance sehingga dapat mendorong keberhasilan revitalisasi. Dalam wawancara dengan ketua Rt setempat, Bapak Saefudin menjelaskan sebagai berikut : "Para pedagang masih belum sepakat soal perpindahan tempat ke Kawasan Penunjang Wisata (KPW), hampir semua pedagang menolak pindah karena tempat yang baru kurang strategis, sampai saat ini juga instalasi listrik dan perlengkapan yang lain belum ada”. 
Berikut adalah hasil wawancara dengan ketua RT dan pedagang Kaki Lima Banten Lama, sebagai berikut :

"Sekarang kami dari paguyuban pedagang Surosowan Banten Lama sedang mendata berapa jumlah pasti seluruh pedagang yang ada"

(Wawancara dengan Bapak Saefudin, Ketua RT dan Pedagang Kaki Lima Banten Lama).

\subsection{Pengembangan Model dan tahap- tahap Inovasi Kebijakan Collaborative Governance}

\section{Revitalisasi Kawasan Wisata Cagar}

\section{Budaya Banten Lama.}

Salah satu prasyarat penting untuk mendorong tumbuhnya inovasi kebijakan adalah kreatifitas birokrasi dalam menciptakan daya perubahan dan gagasan-gagasan baru. (Sururi, 2017). Hal tersebut menunjukkan bahwa inovasi kebijakan adalah proses yang bersifat berkelanjutan bagi pemerintahan daerah. Fortunately, many cases of collaborative governance are created or mandated by national governments, but are implemented locally, thus providing larger $N$ opportunities to analyse them as natural experiments in governance with built-in controls to the analysis, just as was done in this study, while also leveraging variation in institutional design and facilitative leadership to build a more complete theory of collaborative governance (Doberstein, 2016).

Mengadaptasi dari berbagai model collaborative governance, penulis mencoba mengembangkan sebuah model inovasi kebijakan collaborative governance dalam revitalisasi kawasan wisata cagar budaya Banten Lama yang terdiri dari empat komponen penting yaitu komponen pertama kondisi awal yang terdiri dari kondisi eksisting Banten Lama, resource, dasar pertimbangan dan ekonomi politik will; komponen kedua adalah komitmen terhadap proses dan hasil yang terdiri dari trust, kesamaan pemahaman dan legitimasi internal dan eksternal; komponen ketiga adalah desain kelembagaan yang terdiri dari struktural dan prosedural kelembagaan, kepemimpinan, bentuk proses kerjasama; komponen keempat adalah kondisi akhir yang terdiri dari tindak lanjut dan keberlanjutan. 


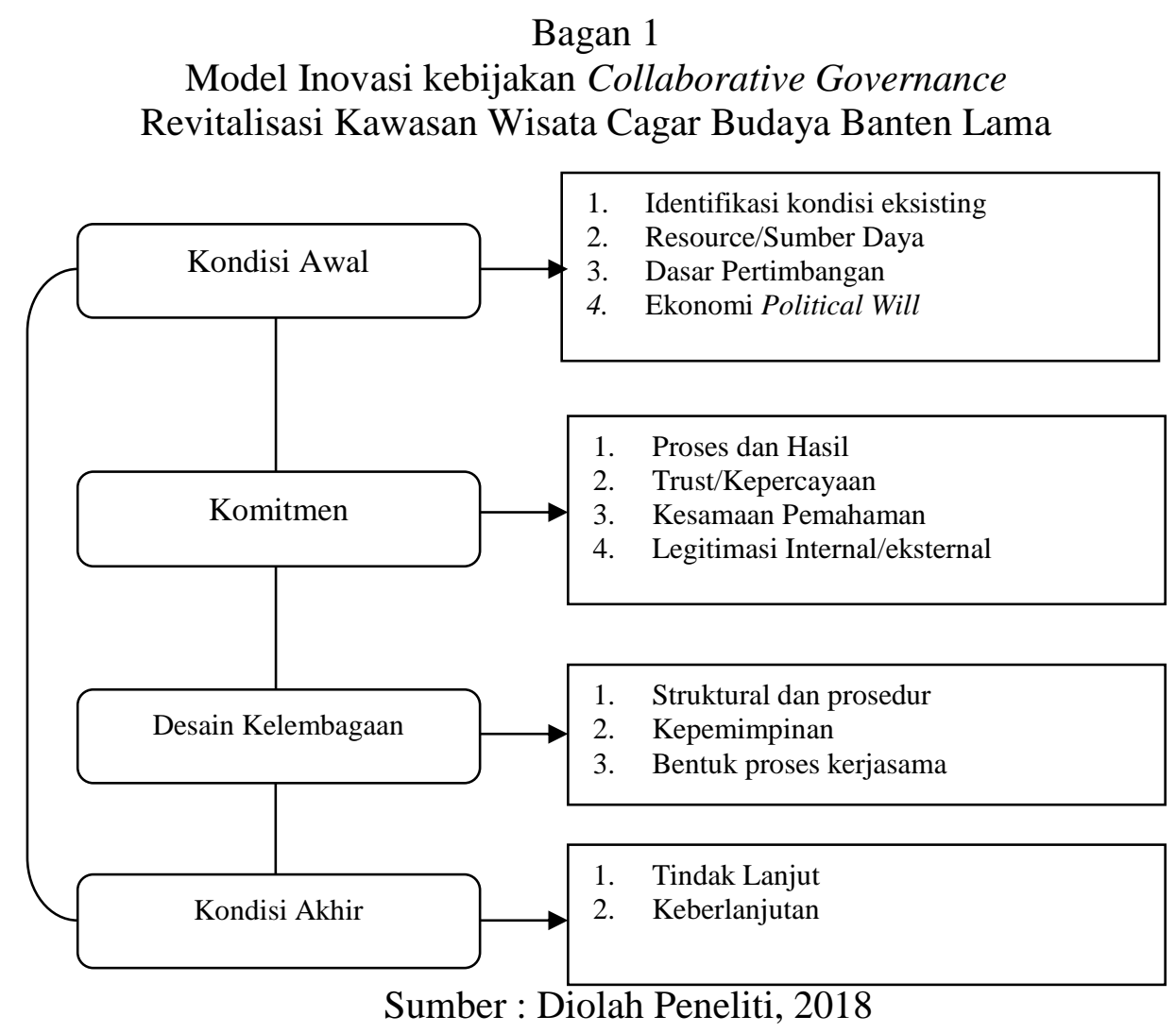

Kondisi awal yang meliputi kondisi kemudian resource atau sumber daya eksisting, resource, dasar pertimbangan dan ekonomi political will merupakan entry point dalam pengembangan inovasi kebijakan collaborative governance, langkah-langkah identifikasi kondisi eksisting Banten Lama seperti pendataan kondisi sarana dan prasarana, jumlah pedagang, jumlah destinasi wisata dan data kependudukan. Termasuk dalam hal ini resource. Dengan melakukan analisis eksisting diharapkan akan memeroleh datadata yang akurat dalam mengestimasi perumusan kebijakan selanjutnya, meliputi potensi unggulan kawasan Banten Lama yang secara ekonomis dan sosial mampu memberikan dampak kesejahteraan masyarakat seperti industri kreatif, dan ekonomi political will berupa dukungan dari pemerintahan daerah dalam bentuk dukungan regulasi dan kebijakan.

Komitmen dari stakeholder kebijakan menjadi proses selanjutnya setelah kondisi awal diidentifikasi. Komitmen ditunjukkan melalui proses dan hasil, pemerintah daerah yang terlibat dalam collaborative governance 
mempunyai rasa tanggung jawab yang tinggi terhadap proses yang sedang berjalan dan hasil yang telah dicapai. Kepercayaan antar pemerintahan daerah untuk mempunyai komitmen yang sama menjadi isu penting dalam pengaturan kewenangan sehingga semua pihak dapat saling memberikan dukungan. Kesamaan pemahaman dan legitimasi internal maupun eksternal dalam mewujudkan komitmen menjadi prasyarat penting agar proses kolaborasi dapat berjalan dengan baik.

Desain kelembagaan meliputi tiga hal yaitu struktural dan prosedur, kepemimpinan dan bentuk proses kerja sama. Kolaborasi yang dilakukan dengan pendekatan partisipasi publik dari pemerintahan daerah terhadap masyarakat dan pedagang kaki lima terkait dengan ketiga hal tersebut akan memberikan dampak positif terhadap masyarakat agar terlibat secara penuh dan mendukung setiap kegiatan yang dilakukan. Dan kondisi akhir yang terdiri dari tindak lanjut dan keberlanjutan akan mengevaluasi bagaimana langkah selanjutnya setelah seluruh kegiatan revitalisasi diselesaikan, termasuk dalam hal ini kebermanfaatan dan dampak yang diterima oleh masyarakat.

\section{Simpulan}

Setelah melakukan identifikasi, maka terdapat 3 (tiga) isu yang menjadi prioritas dan strategis yang harus dilakukan dalam proses Collaborative Governance dalam revitalisasi kawasan wisata cagar budaya Banten Lama yaitu dimensi struktural birokrasi, sosialisasi revitalisasi dan relokasi pedagang kaki lima yang tergabung dalam Paguyuban Pedagang Keraton Surososwan Banten Lama. kemudian pengembangan model inovasi kebijakan collaborative governance dan tahap-tahap revitalisasi meliputi empat komponen yaitu kondisi awal yang terdiri dari identifikasi kondisi eksisting, sumberdaya, dasar pertimbangan dan ekonomi political will; komponen kedua adalah komitmen yang meliputi proses dan hasil, kepercayaan, kesamaan pemahaman dan legitimasi internal/eksternal; komponen ketiga adalah desain kelembagaan yang terdiri dari struktur dan prosedur, kepemimpinan dan bentuk proses kerjasama; dan komponen keempat adalah kondisi akhir yang meliputi tindak lanjut dan keberlanjutan.

\section{Bahwa Collaborative Governance} yang dilakukan antara Pemerintah Daerah Provinsi Banten, Kabupaten Serang dan Kota Serang dalam revitalisasi kawasan 
wisata cagar budaya Banten Lama yang tertuang dalam Memorandum of Understanding (MOU) masih terdapat berbagai hambatan-hambatan dalam implementasinya seperti permasalahan relokasi pedagang kaki lima yang belum mau pindah dari Kawasan Cagar Budaya Banten Lama ke Kawasan Penunjang Wisata (KPW), belum tercapainya target perencanaan pembangunan (revitalisasi) infrastruktur dan belum sinergisnya kerjasama antara stakeholder. Permasalahan-permasalahan tersebut tentu saja akan menghambat revitalisasi kawasan wisata cagar budaya Banten Lama dan harus segera mendapatkan penanganan yang serius. Dalam hal ini keseriusan dengan dibarengi komitmen yang tinggi dari para pejabat publik (Gubernur, Bupati dan Walikota) untuk menyelesaikan permasalahan sangat dibutuhkan, faktor intensitas komunikasi dan koordinasi menjadi kata kunci agar dapat mengambil keputusan yang tepat.

Selain itu pendekatan partisipatif kepada masyarakat perlu terus dilakukan agar inovasi kebijakan Collaborative Governance revitalisasi kawasan cagar budaya Banten Lama memiliki nilai faktor dan dampak strategis. Memiliki nilai faktor dikarenakan terdapat faktor-faktor yang memengaruhi nilai-nilai ekonomi masyarakat lokal, politik dan kebijakan pemerintahan daerah, sosial kemasyarakatan dan budaya setempat. Sedangkan dampak strategis inovasi kebijakan Collaborative Governance adalah mendorong keterlibatan stakeholder kebijakan pemerintah daerah dalam pengembangan kawasan wilayah dan pembangunan berkelanjutan.

\section{Daftar Pustaka}

\section{Jurnal}

Ansell, C., \& Gash, A. (2007). Collaborative Governance in Theory and Practice, 543-571. https://doi.org/10.1093/jopart/mum03 2

Doberstein, C. (2016). Designing Collaborative Governance DecisionMaking in Search of a "Collaborative Advantage." Public Management Review, 18(6), 819-841. https://doi.org/10.1080/14719037.201 5.1045019

Denok Kurniasih, Paulus Israwan Setyoko, dan Moh. Imron, (2017). Collaborative Governance dalam penguatan kelembagaan program sanitasi Lingkungan Berbasis Masyarakat (SLBM) di Kabupaten Banyumas, Jurnal Sosiohumaniora, Volume 19 No. 1 Maret $2017: 1-7$

Emerson, K., Nabatchi, T., \& Balogh, S. 
(2011). An Integrative Framework for Collaborative Governance, (June 2009), 1-29. https:// doi.org/10.1093/jopart/mur011

Gibbings, S. L. (2017). Sosialisasi, Street Vendors and Citizenship in Yogyakarta. Citizenship and Democratization in Southeast Asia, 95-122. https://doi.org/10.1163/97890043296 69

Huxham, C., Vangen, S., Huxham, C., \& Eden, C. (2000). The Challenge of Collaborative Governance. Public Management Review, 2(3), 337-358. https://doi.org/10.1080/14719030000 000021

Keban, Y. T. (1999). Hubungan antara pemerintahan daerah yang satu dengan pemerintah daerah yang lain.

Morse, R. S., \& Stephens, J. B. (2009). Teaching Collaborative Governance: Phases , Competencies, and CaseBased Learning, 18(3), 565-584.

Mutiarawati Tika, Sudarmo, (2017). Collaborative Governance dalam Penanganan Rob di Kelurahan Bandengan Kota Pekalongan, Jurnal Wacana Publik Vol 1 No 2,2017 hlm $48-62$

Newman Dkk, (2004). Public Participation and Collaborative Governance, Jnl Soc. Pol., 33, 2, 203 223 C 2004 Cambridge University Press DOI: 10.1017/S0047279403007499 Printed in the United Kingdom

Prasojo, Eko, (2017). Conference on Administrative Science, Policy, and
Governance Studies (ICASPGS) 2017 di Hotel Margo, 30 Oktober 201

Sambodo Giat Tri \& Pribadi Ulung, 2016. Pelaksanaan Collaborative Governance di Desa Budaya Brosot, Galur, Kulonprogo,DI. YogyakartA, Jurnal Ilmu pemerintahan \& Kebijakan public, Vol. 3 No. 1 Februari 2016

Sururi, A. (2016). Inovasi Kebijakan Publik, Tinjauan Konseptual dan Empiris. Sawala Jurnal Administrasi Negara, 4(3), 1-14.

Sururi, A. (2017). Inovasi Kebijakan dalam Perspektif Administrasi Publik menuju terwujudnya Good Public Policy Governance. Jurnal Spirit Publik Universitas Sebelas Maret, 12, 14-31.

Tresiana Novita \& Duadji Noverman, (2017). Kolaboratif Pengelolaan Pariwisata Teluk Kiluan (Collaborative Management of The Teluk Kiluan Tourism), disampaikan pada seminar nasional tentang membangun etika social menuju masyarakat yang berkeadilan, FISIP UNILA Lampung, 18 Oktober 2017

Torang, Syamsir. (2016). Oganisasi dan Manajemen, Alfabeta Bandung.

Yong-duck Jung, Daniel Mazmanian and Shui-Yan Tang, (2009). Collaborative Governance In The United States And Korea : Cases In Negotiated Policymaking And Service Delivery, Collaborative Governance, WP-April 2009-1

\section{Artikel dalam Koran}

Kabar Banten, 21 Juli 2017. Penataan Banten Lama ditarget rampung 3 
tahun, hal 1

Radar Banten, 22 Maret 2018. Lelang

Ganjal Revitalisasi Banten Lama, hal 1. 